\title{
EFEKTIVITAS MODEL GUIDED DISCOVERY LEARNING UNTUK VIDEO PEMBELAJARAN DALAM MENGETAHUI PERBEDAAN KEMAMPUAN PEMECAHAN MASALAH MATEMATIKA SISWA
}

\author{
Khilya Ulfa $^{1}$, Achmad Buchori ${ }^{2}$, Yanuar Hery Murtianto ${ }^{3}$ \\ 1,2,3 Pendidikan Matematika Universitas PGRI Semarang \\ khilyaauulfa.15@gmail.com ${ }^{1}$, buccherypgri@gmail.com ${ }^{2}$, \\ yanuarherymurtianto@gmail.com ${ }^{3}$
}

\begin{abstract}
ABSTRAK
Tujuan penelitian ini adalah untuk mengetahui apakah terdapat perbedaan antara kemampuan pemecahan masalah matematika siswa pada pembelajaran guided discovery learninguntuk video pembelajaran dan model konvensional, apakah kemampuan pemecahan masalah matematika siswa yang menggunakan model pembelajaran guided discovery learninguntuk video pembelajaran lebih baik dari siswa yang menggunakan model pembelajaran konvensional. apakah kemampuan pemecahan masalah matematika siswa yang dierikan perlakuan mencapai tuntas secara klasikal maupun individual. Teknik pengambilan sampel yang digunakan adalah cluster random samplingterpilih kelas XI Akuntansi 1 yang diberikan perlakuan dan kelas XI Pemasaran 2 yang diberikan model konvensional. Teknik pengumpulan data yang digunakan adalah metode tes dan metode non tes. Berdasarkan uji prasyarat disimpulkan bahwa sampel berdistribusi normal, mempunyai variansi yang sama, dan mempunyai kemampuan awal yang sama. Hasil penelitiannya adalahterdapat perbedaan rata-rata kemampuan pemecahan masalah matematika siswa menggunakan pembelajaran model guided discovery learninguntuk video pembelajaran dan pembelajaran konvensional, model pembelajaran guided discovery learning untuk video pembelajaran lebih baik dari pembelajaran konvensional terhadap kemampuan pemecahan masalah dan kemampuan pemecahan masalah matematika siswa yang menggunakan model guided discovery learning untuk video pembelajaran mencapai tuntas klasikal yaitu dikatakan tuntas jika paling sedikit $85 \%$ siswa tuntas belajar secara individu dari jumlah siswa dalam satu kelas, sedangkan tuntas secara individual yaitu kemampuan pemecahan masalah matematis siswa mencapai rata-rata lebih dari 75 .
\end{abstract}

Kata Kunci: efektivitas; guided discovery learning;video pembelajaran; kemampuan pemecahan masalah

\begin{abstract}
The purpose of this study is to find out whether there is a difference between students' mathematical problem solving skills in guided discovery learning lessons for learning videos and conventional models, whether the problem solving skills of mathematics students using guided discovery learning model for video learning better than students using conventional learning model. whether the mathematical problem solving ability of students who dierikan treatment to complete thoroughly both classical and individual. The sampling technique used is cluster random sampling selected class XI Accounting 1 given treatment and class XI Marketing 2 given conventional model. Data collection techniques used are test methods and non-test methods. Based on the prerequisite test it was concluded that the samples were normally distributed, had the same variance, and had the same initial ability. The result of the research is there is difference of mean of problem solving ability of student mathematics using learning of guided discovery learning model for conventional learning and learning video, guided discovery learning model for video learning better than conventional learning to problem solving ability and problem solving ability of student mathematics using guided discovery learning model for learning video to complete a classical that is said to be complete if at least $85 \%$ of students thoroughly learn individually from the number of students in one class, while solved individually that is the ability of solving mathematical problems students reach an average of more than 75 .
\end{abstract}

Keywords: effectiveness, guided discovery learning, tutorial video, problem solving abilities 


\section{PENDAHULUAN}

Secara umum proses pembelajaran Matematika di kelas dominan berpusat pada guru. Guru selalu mengajar Matematika dengan metode ceramah (Gunantara, 2014). Pembelajaran yang selama ini terjadi yaitu pembelajaran yang terlalu luas yang mengakibatkan terlalu banyak materi diajarkan. Penyampaian materi pengetahuan hanya merupakan sebuah kegiatan transfer ilmu yang artinya guru hanya memindahkan pengetahuan saja kepada siswa tanpa memperhatikan apakah siswa memahami atau tidak pengetahuan yang diberikan tersebut. Proses pembelajaran hanya satu arah, siswa hanya mencontoh dan mencatat bagaimana cara menyelesaikan soal yang telah dikerjakan oleh gurunya (Nurhajati, 2014). Hal tersebut menyebabkan banyak siswa yang pasif dalam mengikuti proses pembelajaran. Mereka lebih banyak diam, hanya mendengarkan penjelasan saja dan tidak mau bertanya apabila belum mengerti (Gunantara, 2014).Pada kondisi seperti itu, kesempatan siswa untuk menemukan dan membangun pengetahuannya sendiri tidak ada. Siswa hanya menerima saja apa yang telah disiapkan oleh guru (Fauziah, 2010). Akibatnya, kemampuan pemecahan masalahnya pun rendah (Gunantara, 2014).Guru harus dapat menumbuhkan kesadaran siswa dalam melakukan aktivitas pembelajaran sehingga siswa tidak hanya memiliki keterampilan melakukan sesuatu tetapi harus memahami mengapa aktivitas itu dilakukan dan apa implikasinya (Yanuar, 2014). Kemampuan pemecahan masalah berarti kecakapan menerapkan pengetahuan yang diperoleh sebelumnya ke dalam situasi yang belum dikenal.Kemampuan memecahkan masalah sangat dibutuhkan oleh siswa.Karena pada dasarnya siswa dituntut untuk berusaha sendiri mencari pemecahan masalah serta pengetahuan yang menyertainya, menghasilkan pengetahuan yang benar-benar bermakna (Hertiavi, 2010).Sekolah seharusnya juga menerapkan teknologi dalam setiap kegiatan pendidikan, tidak hanya sebagai alat perhitungan matematika saja, namun sudah dijadikan sebagai media pembelajaran yang membantu guru dalam menjelaskan suatu konsep di kelas (Buchori, 2010).

Tujuan penelitian ini adalah untuk mengetahui apakah terdapat perbedaan antara kemampuan pemecahan masalah matematika siswa pada pembelajaran guided discovery learning untuk video pembelajaran dan model konvensional, 
apakah kemampuan pemecahan masalah matematika siswa yang menggunakan model pembelajaran guided discovery learning untuk video pembelajaran lebih baik dari siswa yang menggunakan model pembelajaran konvensional. apakah kemampuan pemecahan masalah matematika siswa yang dierikan perlakuan mencapai tuntas secara klasikal maupun individual.

Menyikapi permasalahan yang berkaitan dengan kondisi kegiatan pembelajaran tersebut perlu diupayakan perbaikan dan inovasi dalam proses pembelajaran (Satyawati, 2011). Salah satu model pembelajaran yang dapat digunakan untuk memperbaiki kualitas proses dan hasil belajar adalah pembelajaran matematika melalui penerapan model guided discovery learning (penemuan terbimbing) (Karim, 2011).Pembelajaran guided discovery learning (penemuan terbimbing) adalah suatu pembelajaran tempat guru berperan menyatakan persoalan, kemudian membimbing siswa untuk menemukan penyelesaian persoalan itu dengan perintah-perintah atau lembar kerja siswa dan siswa mengikuti petunjuk dan menemukan sendiri penyelesaiannya (Satyawati, 2011). Melalui proses penemuan terbimbing, siswa dituntut untuk menggunakan ide dan pemahaman yang telah dimiliki untuk menemukan sesuatu yang baru. Sehingga dengan metode penemuan terbimbing memungkinkan siswa memahami apa yang dipelajari dengan baik (Purwatiningsi, 2013). Pada proses pembelajaran agar siswa lebih mudah memahami materi yang disampaikan guru diperlukan juga media pengajaran yang efektif dengan fasilitas multimedia yang berupa gambar, suara dan animasi. Media yang akan digunakan dalam proses pembelajaran yaitu video pembelajaran dengan software Aurora $3 D$ Presentation dan Camtasia Studio. Software Aurora 3D Presentation merupakan salah satu software canggih terbaik yang dapat digunakan untuk membuat atau menciptakan Text 3D, Button dan Logo kreasi sendiri dengan sangat mudah dan cepat. Software tersebut dapat membantu guru dalam menyampaikan materi yang memerlukan dimensi tiga (Muslim, 2017). Software camtasia sangat mudah digunakan untuk mengimpor file gambar, audio dan video. Guru dapat membuat video pembelajaran dan dapat mengeditnya. Dalam tahap editing pembuatan video dapat menambahkan narasi atau musik (Gromik.Nicolas., 2007). 


\section{METODE PENELITIAN}

Setiap penelitian yang dilakukan memiliki suatu hipotesis atau jawaban sementara terhadap penelitian yang akan dilakukan. Dari hipotesis tersebut akan dilakukan penelitian lebih lanjut untuk membuktikan apakah hipotesis tersebut benar adanya atau tidak benar. Dalam penelitian ini hipotesisnya adalah :

$H_{0_{1}}$ : Tidak terdapat perbedaan antara kemampuan pemecahan masalah matematika siswa pada pembelajaran guided discovery learning untuk video pembelajaran dan model pembelajaran konvensional

$H_{a_{1}}$ : Terdapatperbedaan antara kemampuan pemecahan masalah matematika siswa pada pembelajaran guided discovery learning untuk video pembelajaran dan model pembelajaran konvensional

$H_{0_{2}}$ : Kemampuan pemecahan masalah matematika siswa yang menggunakan model pembelajaran guided discovery learning untuk video pembelajaran tidak lebih baik dari siswa yang menggunakan model pembelajaran konvensional.

$H_{a_{2}}$ : Kemampuan pemecahan masalah matematika siswa yang menggunakan model pembelajaran guided discovery learning untuk video pembelajaran lebih baik dari siswa yang menggunakan model pembelajaran konvensional.

$H_{0_{3}}$ : Kemampuan pemecahan masalah matematika siswa yang dierikan perlakuan tidak mencapai tuntas secara klasikal maupun individual.

$H_{a_{3}}$ : Kemampuan pemecahan masalah matematika siswa yang dierikan perlakuan mencapai tuntas secara klasikal maupun individual.

Populasi dalam penelitian ini adalah kemampuan pemecahan masalah matematika siswa kelas XI di SMK Palebon Semarang. Pengambilan sampel dalam penelitian ini adalah menggunakan cluster random sampling. Hal ini dilakukan dengan pertimbangan bahwa kelas sampel yang diambil diampu oleh guru yang sama, mendapat materi yang sama yaitu turunan, kurikulum yang sama, menggunakan buku paket yang sama, peserta didik duduk pada tingkat kelas yang sama dan pembagian kelas tidak ada kelas unggulan. Dengan menggunakan 
teknik cluster random sampling diperoleh dua kelas yaitu kelas XI Akuntansi 1 sebagai kelas eksperimen yang diberikan model guided discovery learning berbantu video pembelajaran dan XI Pemasaran 2 sebagai kelas kontrol yang diberikan model konvensional. Dalam penelitian ini desain eksperimen yang digunakan adalah Quasi Eksperimen dalam bidang pendidikan (Sugiyono, 2015:107). Desain yang digunakan dalam penelitian ini dapat ditampilkan pada bagan berikut :

Tabel 3.1 Desain Penelitian

\begin{tabular}{|c|c|c|}
\hline Kelas & Perlakuan & Tes \\
\hline Eksperimen & $\mathrm{X}_{1}$ & $\mathrm{O}$ \\
\hline Kontrol & $\mathrm{X}_{2}$ & $\mathrm{O}$ \\
\hline
\end{tabular}

Keterangan:

$\mathrm{X}_{1}$ : Pembelajaran matematika dengan menggunakan model pembelajaran guided discovery learning untuk video pembelajaran.

$\mathrm{X}_{2}$ : Pembelajaran matematika dengan menggunakan model konvensional..

$\mathrm{O}$ : Tes akhir

Variabel dalam penelitian ini terdiri dari variabel dependen dan independen. Pada penelitian ini, variabel independen dalam penelitian ini adalah penerapan model guided discovery learning untuk video pembelajaran. Variabel dependen dalam penelitian ini adalahkemampuanpemecahan masalah matematika kelas XI menurut Polya dengan menggunakan empat langkah yaitu memahami masalah, merencanakan strategi penyelesaian, melaksanakan penyelesaian dan membuat kesimpulan. Teknik pengumpulan data yang digunakan dalam penelitian ini adalah menggunakan metode tes dan metode non tes berupa metode dokumentasi yang digunakan untuk memperoleh daftar nama-nama peserta didik yang menjadi sampel dalam penelitian dan juga untuk mendapatkan nilai awal siswa berupa nilai ulangan bab pertama.

\section{HASIL DAN PEMBAHASAN}

Setiap kelompok diberi perlakuan yang berbeda. Kelompok eksperimen dikenai dengan pembelajaran guided discovey learning untuk video pembelajaran 
dan kelompok kontrol dengan pembelajaran model konvensional. Setelah kedua kelompok diberi perlakuan yang berbeda kemudian dilakukan tes akhir untuk mengetahui rata-rata kemampuan pemecahan masalah matematika siswa sebagai data akhir. Hasil tes akhir kemudian dianalisis antara lain pengujian normalitas data akhir yang digunakan untuk menyatakan bahwa sampel berasal dari populasi yang berdistribusi normal.

Tabel 4.1 Hasil Uji Normalitas Data Akhir

\begin{tabular}{|c|c|c|c|c|}
\hline Kelas & $\mathrm{N}$ & $L_{0}$ & $L_{\text {tabel }}$ & Kesimpulan \\
\hline Eksperimen & 38 & 0.114094 & 0.143 & Berdistribusi normal \\
\hline Kontrol & 38 & 0.106468 & 0.1437 & Berdistribusi normal \\
\hline
\end{tabular}

Berdasarkan dari perhitungan untuk kelompok eksperimen yang diperoleh nilai $L_{0}=0,1140$ dan $L_{\text {tabel }}=0,1437$. Hal ini berarti maka $H_{0}$ diterima yang berarti $L_{0}<L_{\text {tabel }}$. Sehingga dapat disimpulkan bahwa sampel berasal dari populasi yang berdistribusi normal. Berdasarkan dari perhitungan untuk kelompok kontrol yang diperoleh nilai $L_{0}=0,1064$ dan $L_{\text {tabel }}=0,1437$. Hal ini berarti maka $H_{0}$ diterima yang berarti $L_{0}<L_{\text {tabel }}$. Sehingga dapat disimpulkan bahwa sampel berasal dari populasi yang berdistribusi normal.

Pengujian homogenitas data akhir digunakan untuk menyatakan bahwa sampel untuk kelompok eksperimen dan kelompok kontrol berasal dari varians yang sama atau homogen.Hasil perhitungan disajikan dalam tabel berikut ini:

Tabel 4.2 Uji Homogenitas Data Awal

\begin{tabular}{|c|c|c|c|}
\hline Sampel & $\chi_{\text {hitung }}^{2}$ & $\chi_{\text {tabel }}^{2}$ & Kesimpulan \\
\hline 1 & 0,9815 & 3,841 & Homogen \\
\hline
\end{tabular}

Berdasarkan dari perhitungan diperoleh nilai $\chi_{\text {hitung }}^{2}=0,9815$ dan $\chi_{\text {tabel }}^{2}=3,841$. Hal ini berarti $\chi_{\text {hitung }}^{2}<\chi_{\text {tabel }}^{2}$, maka $H_{0}$ diterima. Jadi kedua kelompok sampel memiliki varians yang homogen.

Pada penelitian ini tujuan pertama yaitu untuk mengetahui apakah terdapat perbedaan antara kemampuan pemecahan masalah matematika siswa pada pembelajaran guided discovery learning untuk video pembelajaran dan model konvensional. Maka dari itu digunakan uji anava dengan kritera $H_{0}$ diterima apabila $F_{0} \leq F_{\alpha\left(v_{1} ; v_{2}\right)}$ dan $H_{0}$ ditolak apabila $F_{0}>F_{\alpha\left(v_{1} ; v_{2}\right)}$. 
Tabel 4.3 Hasil Perhitungan Uji Anava Data Akhir

\begin{tabular}{|l|l|l|l|l|}
\hline Sumber & Dk & JK & RK & F \\
\hline 1 & 1 & 199,0657895 & 199,0657895 & 4,295076307 \\
\cline { 1 - 4 } & 74 & 3429,710526 & 46,34743954 & \\
\hline & 75 & 3628,776316 & & \\
\hline
\end{tabular}

Hasil uji perbedaan rata-rata kemampuan pemecahan masalah Matematika kelas eksperimen dan kelas kontrol menunjukkan bahwa $F_{h i t u n g}>F_{0,05 ;(1,74)}$ atau 4,2950 >3,9702 maka $\mathrm{H}_{\mathrm{o}}$ ditolak dan $\mathrm{H}_{\mathrm{a}}$ diterima ini berarti ada perbedaan ratarata kemampuan pemecahan masalah Matematika antara kelas eksperimen dan kelas kontrol.

Selanjutnya tujuan kedua dari penelitian ini yaitu untuk mengetahui kemampuan pemecahan masalah siswa dengan model guided discovery learning untuk video pembelajaran lebih baik dibanding dengan pembelajaran langsung. Dalam hal ini digunakan uji scheffe' dengan kriteria $\mathrm{H}_{\mathrm{o}}$ diterima jika $F>(k-$ 1) $F_{\alpha: k-1, N-k}$. Dari perhitungan diperoleh $F_{2-1}=4,2950$,sedangkan daftar distribusi $\mathrm{F}$ dengan derajat pembilang $(\mathrm{k}-1)=1$ dan derajat kebebasan penyebut $(\mathrm{N}-\mathrm{k})=74$ dengan $\alpha$ sebesar $5 \%$ diperoleh nilai $(k-1) F_{(\alpha)\left(v_{1}, v_{2}\right)}=$ $(2-1) F_{(0,05)(1,74)}=3,9702$ maka $F_{2-1}>F_{\text {tabel }}$ yaitu $4,2950>3,9702$ sehingga $\mathrm{H}_{\mathrm{o}}$ diterima, ini berarti ada perbedaan Kemampuan Pemecahan Masalah Matematika antara model pembelajaran Guided Discovery Learning berbantuan Video Pembelajaran dengan model pembelajaran konvensional.

Tujuan ketiga dari penelitian ini yaitu apakah kemampuan pemecahan masalah matematika siswa yang dierikan perlakuan mencapai tuntas secara klasikal maupun individual. Pada ketuntasan Individual dengan kriteria uji $H_{0}$ ditolak jika $t_{\text {hitung }} \geq t_{\text {tabel }}$ dan $H_{0}$ diterima jika $t_{\text {hitung }} \leq t_{\text {tabel }}$. Diperoleh dari perhitungan yaitu thitung $=9,06387$ dan untuk $\alpha=0,05$ peluang 0,95 dengan tabel $=1,684$. Karena $t_{\text {hitung }} \geq t_{\text {tabel }}$ yaitu 9,06387>1,684 maka $H_{0}$ ditolak. Jadi rata-rata kemampuan pemecahan masalah siswa yang pembelajarannya meggunakan model guided discovery learning lebih dari 75. Selanjutnya, untuk ketuntasan belajar klasikal dengan kriteria suatu kelas dikatakan tuntas dalam belajar jika $85 \%$ peserta didik yang ada mencapai kriteria ketuntasan minimal 
yang ditargetkan pada kelas tersebut. Dari perhitungan diketahui siswa yang tuntas 35 dari 38 siswa dan Ketuntasan Belajar Klasikal (KBK) kelas eksperimen 92\%. Jadi, kelas eksperimen dapat dikatakan tuntas secara klasikal.

\section{SIMPULAN}

Berdasarkan hasil penelitian eksperimen yang telah dilaksanakan dapat disimpulkan bahwa terdapat perbedaan rata-rata kemampuan pemecahan masalah matematika siswa menggunakan pembelajaran model guided discovery learning berbantuan video pembelajaran dan pembelajaran konvensional dengan hasil perhitungan anava diperoleh $F_{h i t u n g}=4,29508$, dengan taraf signifikansi 5\%, dk pembilang $=1$ dan dk penyebut $=74$ diperoleh $F_{\text {tabel }}=3,97023$ karena Fhitung $>$ $F_{\text {tabel }}$ yaitu 4,29508 > 3,97022958. Model pembelajaran guided discovery learning berbantu video pembelajaran lebih baik dari pembelajaran konvensional terhadap kemampuan pemecahan masalah dengan hasil $F_{2-1}>F_{\text {tabel }}$ yaitu 4,29508> 3,9702 . Kemampuan pemecahan masalah matematika siswa yang menggunakan model Guided Discovery Learning berbantuan video pembelajaran mencapai tuntas secara klasikal maupun individual dengan hasil ketuntasan belajar individual pada kelas yang menggunakan model Guided Discovery Learning berbantuan video pembelajaran diperoleh thitung $=9,06387$ dengan $\mathrm{t}(0,95 ; 38)=1,684$ sehingga thitung $>\mathrm{t}_{(0,95 ; 38)}$ yaitu 9,06387 $>1,684$. Jadi dapat disimpulkan bahwa ratarata Kemampuan Pemecahan Masalah Matematika siswa kelas eksperimen lebih dari 75 atau mencapai KKM, sedangkan untuk ketuntasan belajar klasikal jumlah siswa yang tuntas 35 dari 38 siswa, dengan begitu dapat dikatakan bahwa kelas ini sudah mencapai ketuntasan belajar secara klasikal sebesar 92\%. Berdasarkan uraian diatas dapat disimpulkan bahwa pembelajaran menggunakan model guided discovery learning berbantuan video pembelajaran lebih efektif dibandingkan pembelajaran dengan model konvensional.

Dalam proses pembelajaran matematika yang awalnya menggunnakan model konvensional hendaknya perlu adanya variasi model pembelajaran salah satunya yaitu dengan meggunakan model guided discovery learning agar pembelajaran lebih terarah dengan adanya bimbingan dari guru. Dalam proses pembelajaran diperlukan juga media pengajaran, salah satu media yang digunakan 
yaitu video pembelajaran berupa Aurora 3D Presentation dan Camtasia Studio agar siswa lebih mudah dalam menangkap pembelajaran.

\section{DAFTAR PUSTAKA}

Arifin, Zainal. (2016). Evaluasi Pembelajaran. Bandung: PT Remaja Rosdakarya. Arikunto, Suharsimi. (2013). Dasar-Dasar Evaluasi Pendidikan. Jakarta: Bumi Aksara.

Buchori, Achmad. (2010). Keefektivan Penggunaan Autograph, Cabri 3D dan Maple Sebagai Media Pembelajaran Matematika.1(1).

Budiyono.(2013). StatistikauntukPenelitianEdisi ke-2. Surakarta: Sebelas Maret University Press.

Fauziah, Anna. (2010). PeningkatanKemampuanPemahaman Dan PemecahanMasalahMatematikSiswa SMP MelaluiStrategi React. Forum Kependidikan, 30(1), 1-13.

Gromik. Nicolas. (2007). Video Tutorials: Camtasia in the ESL Clasroom. The JALT Call Journal, 3(1-2), 132-140.

Gunantara, G., Suarjana, I. M., \&Riastini, P. N. (2014).Penerapan Model Pembelajaran Problem Based Learning untuk Meningkatkan Kemampuan Pemecahan Masalah Matematika Siswa Kelas V. Jurrnal Mimbar PGSD Universitas Pendidikan Ganesha,2(1).1-10.

Hertiavi.(2010). Penerapan Model Pembelajaran Kooperatif Tipe Jigsaw Untuk Peningkatan Kemampuan Pemecahan Masalah Siswa SMP.Jurnal Pendidikan Fisika Indonesia, 6(1).53-57.

Karim, Asrul. (2011). Penerapan Metode Penemuan Terbimbing Dalam Pembelajaran Matematika Untuk Meningkatkan Pemahaman Konsep Dan Kemampuan Berpikir Kritis Siswa Sekolah Dasar.Edisi Khusus, (1), 21-32.

Murtianto, Yanuar Hery dan Lukman Harun.(2014). Pengembangan Strategi Pembelajaran Matematika SMP Berbasis Pendekatan Metakognitif Ditinjau dari Regulasi Diri Siswa.AKSIOMA, 5(2).76-92.

Muslim.,\& Heru. P., (2017).Pengembangan Media Pembelajaran Bentuk Molekul Menggunakan Software Aurora 3D.Jurnal Pedidikan Kimia, 6(1), 5564.

Nurhajati.(2014). Pengaruh Penerapan Pendekatan Konstruktivisme Dengan Model Pembelajaran Kooperatif Berbantuan Program Cabri 3D Terhadap Kemampuan Penalaran Dan Koneksi Matematis Siiswa SMA Di Kota Tasikmalaya.Jurnal Pendidikan dan Keguruan, 1(1), 1-11.

Purwatiningsi, S. (2013).Penerapan Metode Penemuan Terbimbing Untuk Meningkatkan Hasil Belajar Siswa Pada Materi Luas Permukaan Dan Volume Balok.Jurnal Elektronik Pendidikan Matematika Tadulako,1(1), 54-61.

Satyawati. (2011). Pengaruh Model Pembelajaran Penemuan Terbimbing Berbasis LKS Terhadap Hasil Belajar Matematika Siswa Ditinjau Dari Kecerdasan Logis Matematis Pada Siswa Kelas X SMAN 1 Bangli. Jurnal Penelitian Pasca sarjana Undiks, 2(2), 1-17.

Sugiyono. 2015. Metode penelitian Kuantitatif Kualitatif dan R\&D. Bandung: Alfabeta. 